\title{
Thyroid disorders in the first trimester of pregnancy: a cross-sectional study
}

\section{Rashmi Shankarappa*, Spoorthy Parvathreddy} Department of Obstetrics and Gynecology, Jagadguru Jayadeva Murugarajendra Medical College, Davangere,
Karnataka, India

Received: 25 May 2020

Accepted: 03 July 2020

\section{*Correspondence:}

Dr. Rashmi Shankarappa,

E-mail: 123drrashmi@gmail.com

Copyright: (c) the author(s), publisher and licensee Medip Academy. This is an open-access article distributed under the terms of the Creative Commons Attribution Non-Commercial License, which permits unrestricted non-commercial use, distribution, and reproduction in any medium, provided the original work is properly cited.

\begin{abstract}
Background: Thyroid disorders in pregnancy are common and are associated with adverse maternal, fetal and neonatal effects. When the prevalence of thyroid disorders is high, then screening for thyroid disorders in early pregnancy can help improve the obstetrical outcome.

Methods: Five hundred and fifty women in their first trimester of pregnancy were studied. They were investigated for estimation of free triiodo thyronine (FT3), free thyroxine (FT4) and thyroid stimulation hormone (TSH). The upper normal limit for TSH considered was $4.0 \mathrm{mIU} / \mathrm{L}$.

Results: Prevalence of thyroid disorders in the study was $12.6 \%$. Hypothyroidism (12\%) was more common than hyperthyroidism (0.6\%). Subclinical hypothyroidism was present in $10 \%$.

Conclusions: Screening of thyroid disorders is to be considered for all pregnant women. As the prevalence of thyroid disorders is high, early recognition and treatment shall reduce maternal and fetal morbidity.
\end{abstract}

Keywords: Pregnancy, Thyroid, Trimester

\section{INTRODUCTION}

Thyroid disorders are a common clinical problem during pregnancy. They constitute the second most common cause of endocrine dysfunction in women during child bearing age after diabetes mellitus. Pregnancy is a hypermetabolic state and induces various physiological changes in the body organs. Pregnancy has effect on thyroid gland and its activity also.

There is an increase in the size of the thyroid gland by $10 \%$. But it can also increase by $20-40 \%$ based on the geographic location and prevalent iodine deficiency in the respective area. ${ }^{1}$ The activity of the thyroid gland is increased due the stimulatory effect of human chorionic gonadotropin (hCG) and human choriotropin (HCT). There is increase in the metabolic demands and in iodine uptake. Iodine requirement increases up to $50 \%$ during pregnancy. Placental hCG stimulates TSH, resulting in reduced maternal thyrotropin, especially in early pregnancy. TSH and T4 appear in the fetus at around 1013 weeks of gestation and rise abruptly at 20 weeks. Placental transfer of thyroid hormones is limited but sufficient for neuro protection. ${ }^{1,2}$

Thyroid dysfunction has varied impact on maternal and fetal outcome. The major obstetric complications are miscarriage, pre-eclampsia and its associated complications, preterm labour and the fetal complications are prematurity, low birth weight, still birth and perinatal death. ${ }^{3-5}$ Severe maternal hypothyroidism can result in irreversible neurological deficit in the offspring. One in ten women develop TPO antibodies and hypothyroidism develops in $16 \%$ of these women. ${ }^{6}$ Even in the absence of thyroid dysfunction, presence of maternal thyroid peroxidase antibodies (TPO Ab) increases the risk of miscarriage and preterm delivery. 
According to the western literature, the prevalence of hypothyroidism is $2.5 \%$ and hyperthyroidism is $0.1-0.4 \%$. The prevalence of hypothyroidism varies from $4.8-11 \%$ based on few Indian studies. This wide range points towards the deficiency of definitive data regarding prevalence of thyroid disorders, mainly due to the geographic variation in iodine deficient state. Evaluation of thyroid functions in pregnancy is essential in view of maternal and fetal well-being. The present study was carried on to find out the prevalence of thyroid disorders in women in their first trimester of pregnancy.

\section{METHODS}

The study was a cross-sectional study conducted in the department of obstetrics and gynecology, Chigateri general hospital affiliated to the institution. All consecutive women attending OPD with singleton pregnancy of $<13$ weeks of gestation, with no history of thyroid disorders or taking thyroid medications were selected for the study. Women with multiple gestation, chronic medical disorders, not consenting for the study were excluded. Five hundred and fifty women were included in the study. Consent was obtained from all.

Detailed history was taken and relevant physical examination was carried. Ultrasonography was done for all women to confirm singleton pregnancy and period of gestation, and to rule out trophoblastic diseases. Blood samples were sent for thyroid function test which included FT3, FT4 and TSH levels. The reference range for FT3 was 1.71-3.71 pg/ml, FT4 was $0.7-1.4 \mathrm{ng} / \mathrm{ml}$ and TSH was 0.1-4.0 mIU/L. The definitive upper limit value for TSH is still controversial, the consideration of cut off value of $4.0 \mathrm{mIU} / \mathrm{L}$ in this study was based on revised ATA recommendation. ${ }^{1}$

Based on the laboratory values, patients were recognized with subclinical hypothyroidism (high TSH with normal FT3, FT4), overt hypothyroidism (high TSH and low FT3, FT4), subclinical hyperthyroidism (low TSH and normal; FT3, FT4), overt hyperthyroidism (low TSH and high FT3, FT4), euthyroid/normal when all three parameters were within normal range.

\section{RESULTS}

Five hundred and fifty women in their first trimester of pregnancy were studied. The mean age in the study group was 23.2 years. Table 1 shows the patient basic characteristics and also age distribution. Women in the age group of 21-25 years had 6\% prevalence of thyroid disorders. Highest prevalence was seen in this age group. In women above 30 years the prevalence was $2.6 \%$ highest. The mean gestation in the study group was 8.4 weeks.

Out of 550 women, $212(38.5 \%)$ were primigravida and $338(61.5 \%)$ were multigravida. $10(1.8 \%)$ had positive family history of thyroid disorders.
Table 1: Patient characteristics.

\begin{tabular}{|lll|}
\hline \multicolumn{1}{|c|}{$\mathbf{n}$} & $\%$ \\
\hline Mean age (years) & 23.2 & \\
\hline Age distribution (years) & & \\
\hline$<20$ & 34 & 6.2 \\
\hline $21-25$ & 275 & 50 \\
\hline $26-30$ & 189 & 34.4 \\
\hline$>30$ & 52 & 9.4 \\
\hline Gravidity & & \\
\hline Primi & 212 & 38.5 \\
\hline Multi & 338 & 61.5 \\
\hline Mean gestation (weeks) & 8.4 & \\
\hline
\end{tabular}

Table 2: Prevalence of thyroid disorders.

\begin{tabular}{|llll|}
\hline $\begin{array}{l}\text { Type of thyroid } \\
\text { disorder }\end{array}$ & Frequency & $\%$ & $\begin{array}{l}\text { Mean } \\
\text { TSH } \\
\text { (mIU/L) }\end{array}$ \\
\cline { 1 - 2 } Euthyroid & 481 & 87.4 & 1.3 \\
\hline Hypothyroidism (total) & 66 & 12 & \multirow{2}{*}{4.3} \\
\cline { 1 - 2 } Subclinical & 55 & 10 & \multirow{2}{*}{0.03} \\
\cline { 1 - 2 } Overt & 11 & 02 & \\
\cline { 1 - 3 } Hyperthyroidism (total) & 03 & 0.6 & \\
\hline Subclinical & 03 & 0.6 & \\
\hline Overt & 00 & 0.0 & \\
\hline
\end{tabular}

Table 2 shows the prevalence of various thyroid disorders in the study group. The prevalence of thyroid disorders in this study was $12.6 \%$. Prevalence of subclinical hypothyroidism was $10 \%$ and overt hypothyroidism was $2 \%$. Prevalence of hyperthyroidism was $0.6 \%$. The mean TSH was $1.3 \mathrm{mIU} / \mathrm{L}$ in euthyroid, $4.2 \mathrm{mIU} / \mathrm{L}$ in subclinical hypothyroid, $4.4 \mathrm{mIU} / \mathrm{L}$ in overt hypothyroid category.

\section{DISCUSSION}

Prevalence of thyroid disorders has a wide range. Due to the adverse obstetric outcome in women with thyroid disorders, it is essential to identify the disorders and administer appropriate treatment at the earliest. Diegnez et al, concluded in their study that maternal age above 30 years is not a risk factor for thyroid dysfunction. ${ }^{7}$ In the present study the highest prevalence of thyroid disorders was in the age group of 21-25 years. But age matched control study was not done in this study. In the current study the prevalence of thyroid disorders was $12.6 \%$. Dhanwal et al, showed a similar result of $14.6 \%$ in their study. They studied 1000 women in their first trimester and $13.5 \%$ had subclinical hypothyroidism and $0.7 \%$ had overt hypothyroidism. ${ }^{8}$ In contrast Rajput et al, found a prevalence of $26.5 \%$ for thyroid disorders, where they studied 461 women in their first trimester of pregnancy. ${ }^{9}$ Subclinical hypothyroidism was seen in $21.5 \%$ in their study. In current study the prevalence of subclinical hypothyroidism was $10 \%$. Pahwa et al, studied 100 women and found that $10 \%$ had thyroid disorders, of which $6 \%$ showed subclinical hypothyroidism. ${ }^{10}$ Gedam et al, studied 350 women for thyroid disorders and found 
it to be prevalent in $14.2 \%$, similar to this study. ${ }^{11}$ The variations in the prevalence could be because of different upper normal limit of TSH considered for the study. In spite of many studies being done on thyroid disorders in pregnancy, there is lack of definitive evidence regarding normative data for TSH cut-off. At present there are no specific recommendations for screening of thyroid function in pregnancy in India. American thyroid association (ATA) revised their recommendation in 2017 and recommended that the first trimester upper normal limit should be obtained by deduction of $0.5 \mathrm{mIU} / \mathrm{L}$ from the pre-pregnancy TSH value. If it's not known than 4.0 mIU/L should be taken as upper limit of normal. ${ }^{1}$ The cut-off of $2.5 \mathrm{mIU} / \mathrm{L}$ in first trimester as recommended by ATA in 2011 was not accepted in many studies. $3,6,8,10,12,13$

Looking at the Indian scenario, the current evidence is conflicting. Indian reports analysed by Kalra et al, stated that cut off of $4.0 \mathrm{mIU} / \mathrm{L}$ may be too high for Indian women and they suggested an intermediate cut off of 3.0 $\mathrm{mIU} / \mathrm{L}$ for first trimester and $3.5 \mathrm{mIU} / \mathrm{L}$ for second and third trimester. ${ }^{12}$ In a study from China, the TSH value more than $4.8 \mathrm{mIU} / \mathrm{L}$ was taken for the diagnosis of hypothyroidism Negro et al. ${ }^{13}$ In a study from Spain by Lara et al, they concluded $4.7 \mathrm{mIU} / \mathrm{L}$ as the cut-off and they also found that the TSH levels in the first trimester of pregnancy are not useful to detect TPO Ab. ${ }^{14}$

\section{CONCLUSION}

From this study authors conclude that the prevalence of thyroid disorders is high. Since thyroid disorders affect both maternal and fetal health if untreated, universal screening for thyroid disorders is to be considered. As the controversy regarding upper normal limit of TSH continues, as recommended each laboratory should have specific reference ranges set. This study lacked this reference range. It is important that population specific ranges are used otherwise different cut off will lead to different prevalence rates of thyroid disorders in the same population.

\section{ACKNOWLEDGMENTS}

Authors would like to thank all the participants of the study, department of obstetrics and gynecology and the institution for their support and encouragement.

Funding: No funding sources Conflict of interest: None declared

Ethical approval: The study was approved by the Institutional Ethics Committee

\section{REFERENCES}

1. Alexander EK, Pearce EN, Brent GA, Brown RS, Chen H, Dosiou C, et al. Guidelines of the American Thyroid Association for the diagnosis and management of thyroid disease during pregnancy and the postpartum. Thyroid. 2017;27(3):315-89.

2. Sreelatha S, Kamala R, Nadagoudar S. A clinical review of obstetric and perinatal outcome in thyroid disorders. Endocrinol Metab Int J. 2018;6(4):266-82.

3. Khadilkar S. Thyroid-stimulating hormone values in pregnancy: cutoff controversy continues? The J Obstet Gynecol India. 2019;69(5):389-94.

4. Thanuja PM, Rajgopal K, Sadiqunnisa. Thyroid dysfunction in pregnancy and its maternal outcome. J Dent Med Sci. 2014;13(1):11-5.

5. Xuegang Fan and Lina Wu. The impact of thyroid abnormalities during pregnancy on subsequent neuropsychological development of the offspring: a metaanalysis. The J Maternal-Fetal Neonat Med. 2016;29:39716.

6. Nambiar V, Jagtap VS, Sarathi V, Lila AR, Kamalanathan $S$, Bandgar TR, et al. Prevalence and impact of thyroid disorders on maternal outcome in Asian-Indian pregnant women. J Thyroid Res. 2011;2011:4290-7.

7. Dieguez M, Herrero A, Avello N, Suarez P, Delgado E, Menendez E. Prevalence of thyroid dysfunction in women in early pregnancy: does it increase with maternal age? Clin Endocrinol. 2016;84:121-6.

8. Dhanwal DK, Sudha P, Agarwal AK, Dixit V, Banerjee AK. High prevalence of subclinical hypothyroidism during first trimester of pregnancy in North India. Ind J Endocrinol Metab. 2013;17:281-4.

9. Rajput R, Goel V, Nanda S, Rajput M, Seth S. Prevalence of thyroid dysfunction among women during the first trimester of pregnancy at a tertiary care hospital in Haryana. Indian J Endocrinol Metab. 2015;19(3):416-9.

10. Pahwa S, Mangat S. Prevalence of thyroid disorders in pregnancy. Int $\mathbf{J}$ Reprod Contracept Obstet Gynecol. 2018;7(9):3493-6.

11. Gedam JK, Rajput DA. Prevalence of thyroid disorders among patients attending the antenatal clinic at tertiary care centre, Parel, Mumbai, India. Int J Reprod Contracept Obstet Gynecol. 2017;6(4):1235-9.

12. Kalra S, Agarwal S, Aggarwal R, Ranbir S. Trimesterspecific thyroid-stimulating hormone: an Indian perspective. Indian J Endocrinol Metab. 2018;22(1):1-4.

13. Negro R, Schwartz A, Gismondi R, Tinelle A, Mangieri T, Stagnaro-Green A. Universal screening versus case finding for detection and treatment of thyroid hormonal dysfunction during pregnancy. J Clin Endocrinol Metab. 2010;95(4):1699-707.

14. Lara MC, Sanchez AV, Solano CC, Pazos ES, Álvarez MI, Macías CG, et al. Hypothyroidism screening during first trimester of pregnancy. BMC Preg Childbirth. $2017 ; 17: 438$.

Cite this article as: Shankarappa R, Parvathreddy S. Thyroid disorders in the first trimester of pregnancy: a cross-sectional study. Int J Reprod Contracept Obstet Gynecol 2020;9:3288-90. 